\title{
Furosemide stress test and interstitial fibrosis in kidney biopsies in chronic kidney disease
}

\author{
Jesús Rivero ${ }^{1}$, Francisco Rodríguez ${ }^{2}$, Virgilia Soto ${ }^{2}$, Etienne Macedo ${ }^{3}$, Lakhmir S. Chawla ${ }^{3}$, Ravindra L. Mehta ${ }^{3}$,
} Sucheta Vaingankar ${ }^{2}$, Pranav S. Garimella ${ }^{3}$, Carlos Garza ${ }^{2}$ and Magdalena Madero ${ }^{2 *}$

\begin{abstract}
Background: Interstitial fibrosis (IF) on kidney biopsy is one of the most potent risk factors for kidney disease progression. The furosemide stress test (FST) is a validated tool that predicts the severity of acute kidney injury (especially at $2 \mathrm{~h}$ ) in critically ill patients. Since furosemide is secreted through the kidney tubules, the response to FST represents the tubular secretory capacity. To our knowledge there is no data on the correlation between functional tubular capacity assessed by the FST with IF on kidney biopsies from patients with chronic kidney disease (CKD). The aim of this study was to determine the association between urine output (UO), Furosemide Excreted Mass (FEM) and IF on kidney biopsies after a FST.

Methods: This study included 84 patients who underwent kidney biopsy for clinical indications and a FST. The percentage of fibrosis was determined by morphometry technique and reviewed by a nephropathologist. All patients underwent a FST prior to the biopsy. Urine volume and urinary sodium were measured in addition to urine concentrations of furosemide at different times $(2,4$ and $6 \mathrm{~h})$. We used an established equation to determine the FEM. Values were expressed as mean, standard deviation or percentage and Pearson Correlation.

Results: The mean age of the participants was 38 years and $44 \%$ were male. The prevalence of diabetes mellitus, hypertension and diuretic use was significantly higher with more advanced degree of fibrosis. Nephrotic syndrome and acute kidney graft dysfunction were the most frequent indications for biopsy. eGFR was inversely related to the degree of fibrosis. Subjects with the highest degree of fibrosis (grade 3) showed a significant lower UO at first hour of the FST when compared to lower degrees of fibrosis $(p=0.015)$. Likewise, the total $U O$ and the FEM was progressively lower with higher degrees of fibrosis. An inversely linear correlation between FEM and the degree of fibrosis $(r=-0.245, p=0.02$ ) was observed.
\end{abstract}

Conclusions: Our findings indicate that interstitial fibrosis correlates with total urine output and FEM. Further studies are needed to determine if UO and FST could be a non-invasive tool to evaluate interstitial fibrosis.

Trial registration: ClinicalTrials.gov NCT02417883.

Keywords: Interstitial fibrosis, Uresis, Kidney biopsy, Furosemide stress test

\footnotetext{
*Correspondence: madero.magdalena@gmail.com

${ }^{2}$ Nephrology Department, National Institute Cardiology Ignacio Chávez, Juan

Badiano No. 1, 14080-Tlalpan, Mexico City, Mexico

Full list of author information is available at the end of the article
}

(c) The Author(s). 2020 Open Access This article is distributed under the terms of the Creative Commons Attribution 4.0 International License (http://creativecommons.org/licenses/by/4.0/), which permits unrestricted use, distribution, and reproduction in any medium, provided you give appropriate credit to the original author(s) and the source, provide a link to the Creative Commons license, and indicate if changes were made. The Creative Commons Public Domain Dedication waiver (http://creativecommons.org/publicdomain/zero/1.0/) applies to the data made available in this article, unless otherwise stated. 


\section{Background}

Chronic kidney disease (CKD), particularly in advanced stages, is considered one of the most serious public health problems worldwide [1, 2].For a long time, efforts have been made understand the risk factors associated to the development of kidney fibrosis, since it is considered one of the most potent risk factors for CKD progression, independent from the CKD etiology, as it represents a final common pathway from injury [3]. The tubules and interstitial compartment together constitute approximately $80 \%$ of the renal mass and is, therefore, more than a complex support system structures [4-6].There are three main recognized histological structures that can be assessed for fibrosis: glomerulosclerosis, vascular sclerosis andtubular atrophy/tubulointerstitial fibrosis (IFTA) $[7,8] . I F T A$ is the final result of an anatomic and functional imbalance where the kidney insults exceed the known compensatory mechanisms of repair where different mediators generate the transition from the normal tubular structure to myofibroblasts and elements of the extracellular matrix $[9,10]$. At this point changes are irreversible and therefore strongly associated to kidney disease progression [11].Trials performed in patients undergoing kidney transplantation suggest that IFTA is strongly implicated with graft failure, progression, and increased mortality [12-14].

For several decades the evaluation of kidney function has been based primarily on measurement glomerular filtration rate (mGFR) or on equations based either on creatinine or cystatin $\mathrm{C}$ where glomerular filtration rate is estimated [15-29]. These methods however do not measure tubular function nor estimate the degree of tubular atrophy or interstitial fibrosis. Some evaluation tools to assess tubular function have been tested such as dilution capacity, concentration [18-31] and urinary acidification [31-33], in addition to excreted fraction of sodium and urea (FENA and FEUN) [34-36], however these have not been widely used in clinical practice. The furosemide stress test (FST) has demonstrated to predict the severity and acute kidney injury (especially at $2 \mathrm{~h}$ ) in critically ill patients and has proved to be superior to urinary biomarkers [37].Furosemide must be actively transported by the human organic anion transporters (hOAT) in the proximal tubule into the tubular lumen in order to be excreted. Since the urinary excretion of furosemide is mediated by the proximal tubule organic anion transport system, we evaluated if the urinary excretion of furosemide and the associated diuretic response were related to the severity of tubulointerstitial damage determined in renal biopsies. We set out to assess the timing and magnitude of furosemide excretion and urine output and determine if these measures may be informative with regard to IF in patients undergoing kidney biopsy.

\section{Methods}

\section{Methods}

We included inpatients that were admitted to the hospital for a kidney biopsy with a clinical indication (allograft and native). Patients were admitted to the nephrology ward at the Instituto Nacional de Cardiologia Ignacio Chavez. Patients needed to be older than 18 years, had a creatinine eGFR $\geq 15 \mathrm{ml} / \mathrm{min}$ by CKD-EPI [38] and had to be hemodynamically stable. Subjects were excluded if they did not accept to participate in the study or if the medical team did not feel the patient was suitable for the study, if they had a known allergy to furosemide, were on renal replacement therapy or were pregnant (Fig. 1). The study was conducted between April 2015 and August 2017.

The research was approved by the institutional research ethics committee and registered with the number 15-920. Written informed consent was obtained from all participants.

\section{Intervention}

Furosemide test was performed during the hospitalization for the kidney biopsy. Most of the FST were done 1 day after the kidney biopsy was performed in full agreement by the medical team. In order to avoid urine measurement errors in those patients who did not have a bladder catheter on the day of the test, a post-voiding bladder volume measurement was performed using pelvic sonography.

All the 84 kidney biopsies were done at the bedside of the patient using ultrasound guidance (Sonosite ${ }^{\oplus}$ ). For the kidney biopsies we used a Biopsy Gun (BARD

Patients admitted to the nephrology ward that underwent a kidney biopsy $(n=105)$

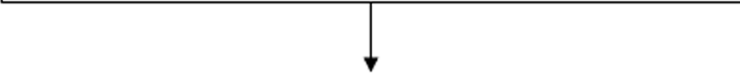

21 Patients were excluded :

- 5 patients did not accept to participate in the study

- 4 patients were not accepted in the trial by their treating physician

- 3 patiens had hemodynamic instability

- 2 patients were hypovolemic

- 1 patient had known allergy to furosemide

- 1 patient was pregnant

- 5 patients were on renal replacement therapy

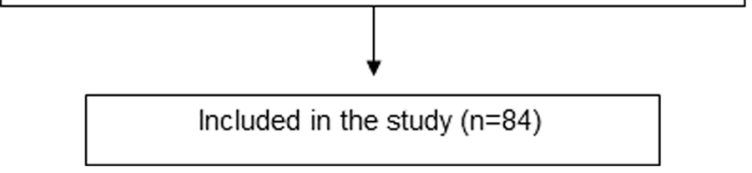

Fig. 1 Patients Flow Diagram 
Magnum $^{\circ}$ ) and needles, procedures were done under local anesthesia.

\section{Furosemide stress test}

Intravenous furosemide was administered at a dose of $1 \mathrm{mg} / \mathrm{kg}$ if subjects had not been exposed to diuretics during the previous 7 days and at a dose of $1.5 \mathrm{mg} / \mathrm{kg}$ if they have been exposed to loop diuretics within the 7 days prior to the study [37]. Medical surveillance and strict hourly UO quantification was done. UO was collected at baseline and every hour until the sixth hour (Fig. 2). Volume status was evaluated by the treating physician, patients that were hypovolemic or had hemodynamic instability were excluded from the study $(n=5), 76$ subjects were euvolemic and 8 subjects were hypervolemic. Fluid replacement on euvolemic subjects as given on a 1:1 cc based on the previous hourly urine output. Hypervolemic patients did not receive intravenous fluid replacement.

\section{Histopathological analysis \\ Kidney specimen}

The kidney biopsy was processed by the pathology department at the Instituto Nacional de Cardiología Ignacio Chávez. All kidney biopsy tissues were considered sufficient for histopathologic evaluation. An experienced renal pathologist blinded to the FST results described the degree of interstitial fibrosis, through direct visualization of light microscopy, with emphasis on the staining of Masson's Trichrome. In addition, fibrosis percentage was assessed by anoptic lector machine (Morphometry) using the Analyzer Olympus BX51 Microscope, image Software Image-PN- Plus 6 and Camera: VF Evolution C (half Cybernetics). This technique has been accepted as a standard as it is more reproducible [39]. IF score was categorized into three groups according to fibrosis percentage: Grade I $<25 \%$, Grade $2,26-50 \%$ and grade $3>50 \%$. Since tubular atrophy (TA) and IF are so highly correlated, TA is not routinely described in our pathology reports.

Urine Furosemide Excretion: UO was collected at every hour on the hour for $6 \mathrm{~h}$ and stored separately in aliquots. Furosemide analyses were determined in individual samples collected at hour $2(0-2 \mathrm{~h}), 4(2-4 \mathrm{~h}), 6$ (4-6 h) and in a mix of all urines.

\section{HPLC analysis of furosemide in urine samples}

Urine samples were purified using Oasis MCX Cartridge (Part\#186000254 Oasis MCX $3 \mathrm{cc}$ cartridge $60 \mathrm{mg}$ $30 \mu \mathrm{m})$. The cartridge was washed with $2 \mathrm{ml}$ methanol

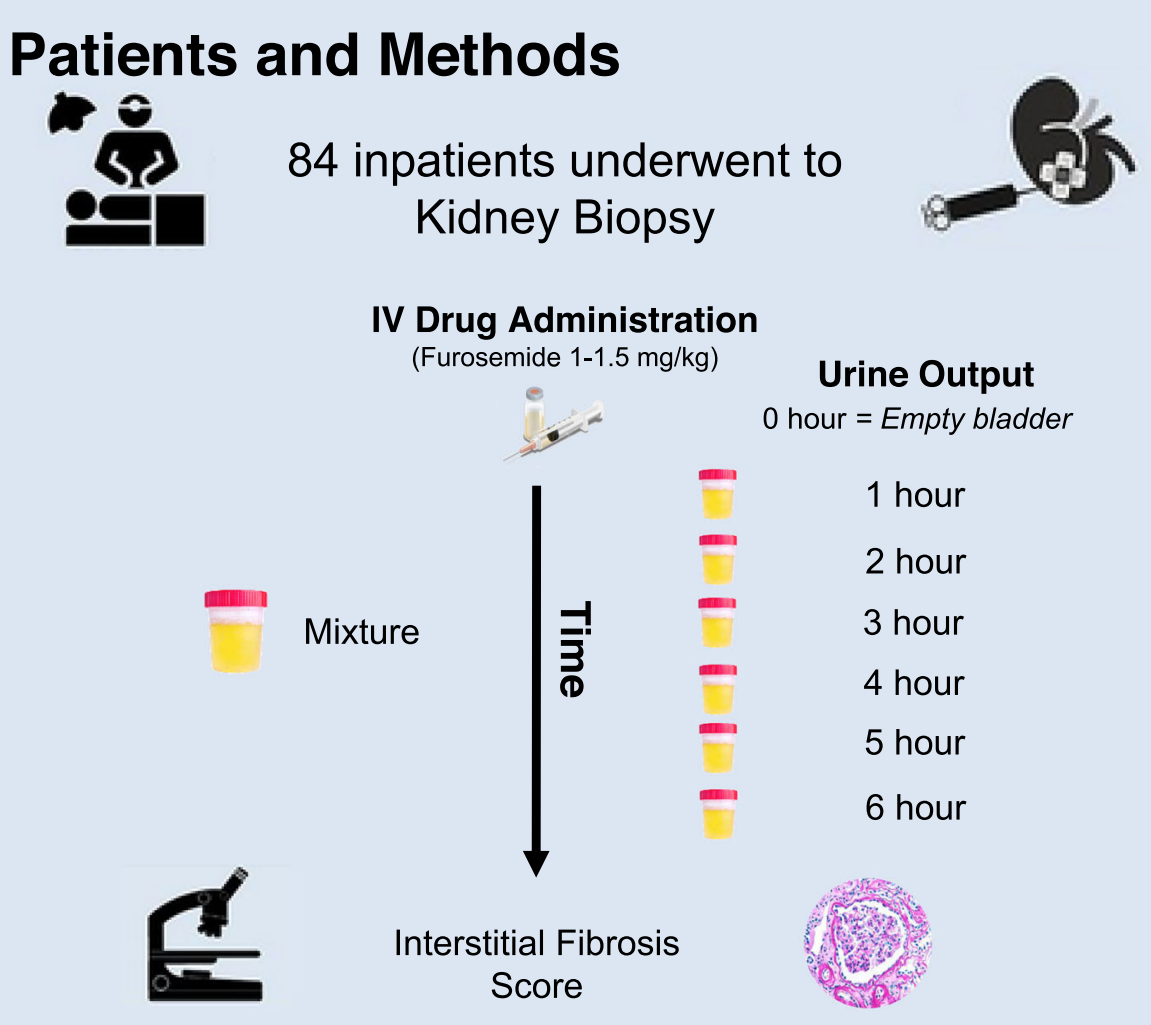

Fig. 2 Furosemide Stress Test Procedure 
followed by $2 \mathrm{ml}$ of milliQ water and loaded with the urine sample $(0.5 \mathrm{ml}$ adjusted to $\mathrm{pH} 6.0$ with $2 \mathrm{M} \mathrm{HCl}$ and diluted with $0.5 \mathrm{ml}$ of MilliQ water). Next, the cartridge was washed with $1 \mathrm{ml}$ of $2 \%$ formic acid to remove acidic compounds followed by $1 \mathrm{ml}$ of methanol to remove neutrals and the bound furosemide was eluted with $1 \mathrm{ml}$ of $5 \%$ ammonium hydroxide in methanol. The eluted ammonium hydroxide fraction was dried in a speed-vac, reconstituted in 100ul of MilliQ water and quantified by validated HPLC test [40]. The HPLC column used was Thermo Scientific Acclaim $120 \mathrm{~T}$, 3X150mm, C18, 3um, 120A, with TSK $120 \mathrm{~T}$ guard cartridge. The flow rate was $0.5 \mathrm{ml} / \mathrm{min}$, column temperature $40^{\circ} \mathrm{C}$ and run time $15 \mathrm{~min}$. The isocratic elution solvent was $30 \%$ acetonitrile and $70 \%$ potassium phosphate monobasic buffer ( $10 \mathrm{mM}, \mathrm{pH} 3.85)$. Sample volume 50ul was injected and furosemide was detected at UV $233 \mathrm{~nm}$, retention time $6.3 \mathrm{~min}$.

We estimated the furosemide excreted mass equation (FEM) expressed as percentage using the following equation:

$$
\mathrm{FEM} \%=\frac{\text { UrineFurosemide } x \text { Urinary Volume }}{\text { Administred Furosemidedose }} \times 100
$$

\section{Statistical analysis}

All values were expressed as means, standard deviation, and percentages. Results were expressed as average, standard deviation (SD) or as proportions as appropriate. The comparisons were made using chi [2] for proportions and by means of student $\mathrm{T}$ test for independent samples (comparison between groups) according to the response to furosemide. The Pearson test was used to determine the correlation between degree of fibrosis and response to FST. We used statistical program SPSS 16 version.

\section{Results}

The mean age was 38 years, $44 \%$ were male and the mean eGFR was $64 \pm 42 \mathrm{ml} / \mathrm{min} / 1.72 \mathrm{~m}^{2}$. The presence of diabetes mellitus, hypertension and use of diuretics was predominantly higher in grade III fibrosis. No episodes of hypotension or hipokalemia occurred during the study. As expected, eGFR decreased as interstitial fibrosis increased (Table 1). Nephrotic syndrome and acute kidney graft dysfunction were the most frequent indications for biopsy.

We observed that subjects with grade 3 fibrosis showed a significant lower urine volume at hours 1,4 and total urine when compared with grades I and II $(155 \mathrm{~mL} \pm 181$ vs $316 \mathrm{~mL} \pm 262$ vs $328 \pm 353)$ (Table 2).

The (FEM) was progressively lower with higher degrees of fibrosis, at hours 2 and 4 (1.6 and 0.8 for grade III fibrosis vs 6.8 and 4.0) (Table 2 and Fig. 3). When analyzed separately the correlation between FEM2 and fibrosis was significant $(p=0.04)$ in the native kidneys but not in the transplant group $(p=0.26)$ (Table 3).

We did not find a significant difference between the measurement of subjective fibrosis and morphometry $(27.7 \pm 19.8 p=0.795$ vs $26.2 \pm 17.2 p=0.608)$.

A sub analysis was performed to evaluate the behavior of the FEM at different times with respect to the cut-off

Table 1 Baseline Characteristics

\begin{tabular}{|c|c|c|c|c|}
\hline Variable & Kidney allograft $(n=30)$ & Native kidneys $(n=54)$ & Total group $(n=84)$ & P \\
\hline Age (y) & $34.6 \pm 14.8$ & $40.9 \pm 15$ & $38.6 \pm 15.1$ & 0.071 \\
\hline Gender (M/F) N (\%) & $18(60) / 12(40)$ & $19(35.2) / 35$ (64.8) & $37(44) / 47(56)$ & $0.028^{*}$ \\
\hline Baseline eGFR (ml/min/1.73m²) & $47.2 \pm 26.8$ & $73.2 \pm 45.6$ & $63.9 \pm 41.6$ & $0.001^{*}$ \\
\hline Serum Albumin (g/dl) & $3.8 \pm 0.7$ & $2.9 \pm 0.8$ & $3.2 \pm 0.9$ & $0.000^{*}$ \\
\hline $\begin{array}{l}\text { Urinary protein excretion } \\
\text { (g/g creatinine) }\end{array}$ & $1.62 \pm 2.63$ & $4.55 \pm 4.52$ & $3.47 \pm 4.16$ & $0.002^{*}$ \\
\hline Diabetes Mellitus N (\%) & $23(76.7)$ & - & $23(76.7)$ & $0.000^{*}$ \\
\hline Hypertension N (\%) & - & $20(37)$ & $20(37)$ & $0.000^{*}$ \\
\hline $\begin{array}{l}\text { Systemic lupus } \\
\text { erythematosus N (\%) }\end{array}$ & $1(3.3)$ & $21(38.9)$ & $22(26.2)$ & $0.000^{*}$ \\
\hline \multicolumn{5}{|l|}{ Interstitial Fibrosis N (\%) } \\
\hline Grade I & $13(43.3)$ & $32(59.3)$ & $45(53.6)$ & $0.003^{*}$ \\
\hline Grade II & $16(53.3)$ & $11(20.4)$ & $27(32.1)$ & $0.003^{*}$ \\
\hline Grade III & $1(3.3)$ & $11(20.4)$ & $12(14.3)$ & $0.003^{*}$ \\
\hline Combined & $25.3 \pm 15.4$ & $28.7 \pm 22.3$ & $27.5 \pm 20.1$ & 0.409 \\
\hline
\end{tabular}

Data are expressed as mean \pm standard deviation, frequency or percentage as appropriate

eGFR estimated glomerular filtration rate, AKI acute kidney injury, FEM furosemide excreted mass, IFI interstitial fibrosis $<25 \%$, IFII interstitial fibrosis $26-50 \%$, IFIII interstitial fibrosis $>50 \%$

${ }^{*} p<0.05$ kidney allograft vs. native kidneys 
Table 2 Urine Output and Furosemide Excreted Mass

\begin{tabular}{|c|c|c|c|c|c|}
\hline Variable & Combined $n=84$ & IF Grade I $n=45$ & IF Grade $\| n=27$ & IF Grade IIIn = 12 & $P$ \\
\hline \multicolumn{6}{|l|}{ Urine measurements } \\
\hline Uresis $1 \mathrm{~h}$ & $313 \pm 296.7$ & $316.4 \pm 261.9$ & $328.5 \pm 352.7$ & $155 \pm 181$ & 0.015 \\
\hline Uresis 2-h (mL) & $355 \pm 254$ & $387 \pm 284$ & $374 \pm 216$ & $260 \pm 229$ & 0.413 \\
\hline Uresis 4-h (mL) & $250 \pm 212$ & $291 \pm 202$ & $241 \pm 243$ & $125 \pm 106$ & 0.054 \\
\hline Uresis 6-h (mL) & $200 \pm 179$ & $195 \pm 179$ & $228 \pm 182$ & $155 \pm 180$ & 0.492 \\
\hline Total Uresis (mL) & $1509 \pm 779$ & $1599 \pm 790$ & $1591 \pm 816$ & $995 \pm 415$ & 0.045 \\
\hline FEM-2 h (\%) & $5.5 \pm 6.5$ & $6.8 \pm 7.4$ & $5.1 \pm 5,7$ & $1.6 \pm 1.7$ & 0.049 \\
\hline FEM-4 h (\%) & $2.9 \pm 4.0$ & $4.0 \pm 4.6$ & $1.9 \pm 2.9$ & $0.8 \pm 1.3$ & 0.012 \\
\hline
\end{tabular}

point that showed the best area under the curve in previously reported cohorts in the literature with acute kidney injury (200 $\mathrm{ml}$ of uresis), identifying that the FEM at the second hour was the measurement that best correlated with this cut point. (Table 4).

An inverse correlation between $\mathrm{UO}$ and the degree of fibrosis (the greater the response in urinary output, the lower the degree of fibrosis) was observed (quadratic correlation of 0.072 , per each $\mathrm{ml}$ change in UO there was a 0.2 change in fibrosis).

\section{Sensitivity analysis}

Since albumin is necessary for the secretion of furosemide, we evaluated the Pearson correlation between serum albumin with urine output and FEM. There was a significant correlation between serum albumin and total UO $(p=.008)$ (At higher serum albumin we observed higher UO) but there was no significant correlation between albumin and FEM $(p=0.64)$. Likewise, there was no correlation between levels of proteinuria and FEM $(p=0.48)$. When analyzed separately, the correlation between proteinuria and FEM in native versus transplant kidneys was not different $(p=0.25$ vs $p=0.86$, respectively). As expected, there was a significant correlation between eGFR (CKDEPI) and $\mathrm{FEM}_{2}(p=0.001)$ and between eGFR and fibrosis $(\mathrm{p}=<0.001)$ (Fig. 4a, b). Finally, since most of the allograft biopsies were performed for allograft dysfunction we evaluated the rate of acute kidney injury in our population. Creatinines were assessed 3 months before and 3 months after the study using a nonparametric test (Wilcoxon range test) for comparisons. In all

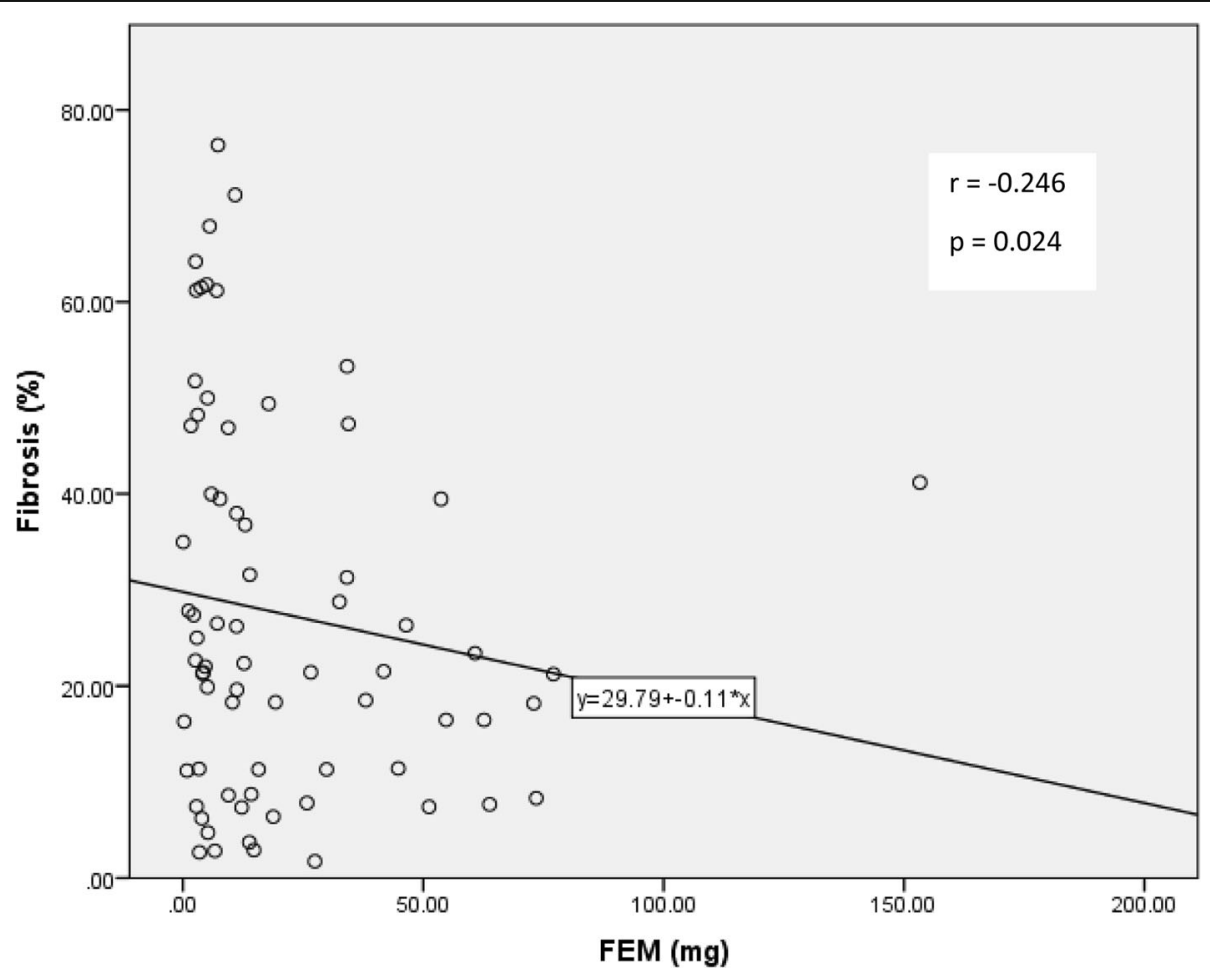

Fig. 3 Correlation analysis of interstitial fibrosis and FEM 
Table 3 Pearson's correlation coefficient between MFP and FEM2, eGFR and total uresis for native kidneys and allografts

MFP Total FEM-2 $(\mathrm{mg}) \quad$ eGFR $(\mathrm{mL} / \mathrm{min}$ Total uresis

$(n=84) \quad 11.73 \mathrm{~m} 2) \quad(\mathrm{mL})$

Natives $(n=54) \quad-0.27(p=0.043)-0.56(p=0.000)-0.34(p=0.012)$

Allografts $(n=30) \quad-0.21(p=0.264)-0.34(p=0.059) \quad-0.09(p=0.613)$

MFP morphometric fibrosis percentage, FEM2 furosemide excreted mass at $2 \mathrm{~h}$, eGFR estimated glomerular filtration rate

the comparisons of related samples we found $p$ values greater than $0.1(\mathrm{p}=\mathrm{NS})$. Results were no different between allograft and native kidneys.

\section{Discussion}

In our study we were able to establish the association between a functional tubular assessment with the FST and the degree of interstitial fibrosis obtained in kidney biopsies. Urine volume correlated with the degree of fibrosis and the excreted mass of furosemide decreased as fibrosis increased. To our knowledge this is the first study to establish a tubular anatomic-functional relationship.

We found that the furosemide excreted mass at $2 \mathrm{~h}$ $\left(\mathrm{FEM}_{2}\right)$ correlated with low urine output during the same time frame. The $\mathrm{FEM}_{2}$ is conceived to function similarly to the forced exhaled volume $\left(\mathrm{FEV}_{1}\right)$ in pulmonary function tests. A healthy person can expire most of the air from their lung in $1 \mathrm{~s}$. Similarly, a healthy person with a full complement of functioning nephrons can rapidly eliminate furosemide into the urine. However, when tubular dysfunction is present as the case with tubular-interstitial fibrosis, the fibrosed kidney loses its capacity to efficiently move furosemide out of the plasma and into the tubular lumen. This type of functional testing may form the basis of assessing tubular function in a non-invasive fashion.

The evaluation of the tubular functional capacity however is rarely done in the clinical setting and the estimation of kidney function for patients with CKD is primarily based on the eGFR. There are different ways to evaluate the tubular function, such as the kidney concentration capacity, acidification capacity, calculation of relative clearance of a substance such as beta 2 microglobulin [41] or creatinine. In addition, urine uromodulin which is the most abundant protein secreted by the tubules has been described as a

Table 4 Mass of Excretion of Furosemide according to urine output cutoff at hour 2

\begin{tabular}{llll}
\hline $\begin{array}{l}\text { Measurement } \\
\text { time point }\end{array}$ & $\begin{array}{l}\text { Positive }(\text { Urine } \\
\text { Output }>200 \mathrm{ml})\end{array}$ & $\begin{array}{l}\text { Negative }(\text { Urine } \\
\text { Output }<200 \mathrm{ml})\end{array}$ & $P$ \\
\hline FEM-2 & $7.2 \pm 6.9(n=61)$ & $1.1 \pm 2.2(n=23)$ & $<0.0001$ \\
FEM-4 & $2.9 \pm 3.8(n=61)$ & $2.7 \pm 4.5(n=23)$ & 0.847 \\
FEM-6 & $1.8 \pm 2.8(n=54)$ & $2.2 \pm 3.7(n=18)$ & 0.592 \\
FEM Mixture & $21.2 \pm 22.0(n=51)$ & $20.8 \pm 34.9(n=20)$ & 0.949 \\
\hline
\end{tabular}

marker of tubular function and has been associated with eGFR decline and cardiovascular outcomes [42].

Some of the first studies to evaluate tubular function were done by our group and others 30 years ago. In those studies, the tubular functional capacity was evaluated looking at the difference between creatinine clearance and inulin clearance [43]. In those studies, the glomerular reserve was assessed with a protein challenge. These studies were conducted in three groups of patients: healthy patients, kidney donors and patients with CKD demonstrating in the latter a lower ability to increase GFR before protein administration and a limited creatinine tubular clearance [44]. However, these tests remain a research tool and can be cumbersome due to the protein loading as such have limited clinical applicability.

The idea to evaluate tubular function with the use of intravenous furosemide relies on the ability of the drug to be secreted in the proximal tubule. In order for furosemide to increase urine output, furosemide must be actively secreted into the proximal lumen, and the functions of the thick ascending limb, luminal patency and collecting duct should be preserved. The furosemide stress test has been used in clinical practice only in the context of acute kidney injury and has been shown to predict outcomes in this population. A standard dose of intravenous furosemide was delivered to critically ill patients with KDIGO stage I or II AKI, and then urine output response was assessed. A 2 -h urine output $<100 \mathrm{ml} / \mathrm{h}$ in response to a furosemide challenge predicts progression to KDIGO stage III AKI within 14 days with a receiver operator characteristic area under of the curve (AUC) of 0.87 [37]. This test performed better than many of the urinary biomarkers used to predict AKI. Subsequent studies of FST in AKI have demonstrated that the FST performance is robust and performs consistently for the assessment of AKI progression and recovery [45-48].However, none these studies measured the excreted mass of furosemide.

The assessment and monitoring of CKD are primarily focused on GFR and degree of proteinuria. While not demonstrated in this study, the FST may offer a noninvasive functional tool for the clinician to assess tubular function in patients with kidney disease. Nonetheless, the FST appears to offer novel information in these patients.

Our study has several strengths. First, the study explores a novel concept of tubular function and its association with interstitial fibrosis in kidney biopsies. Second, the amount of fibrosis on the kidney biopsies was assessed also by morphometry removing the potential observation bias by the pathologist. Third, in addition to urine output, we measured the urine excreted mass of furosemide. Lastly, this analysis does demonstrate that the FST offers more information as compared to classic GFR assessment.

Our study also has limitations. First this is a cross sectional study and we do not have data on the impact 
a

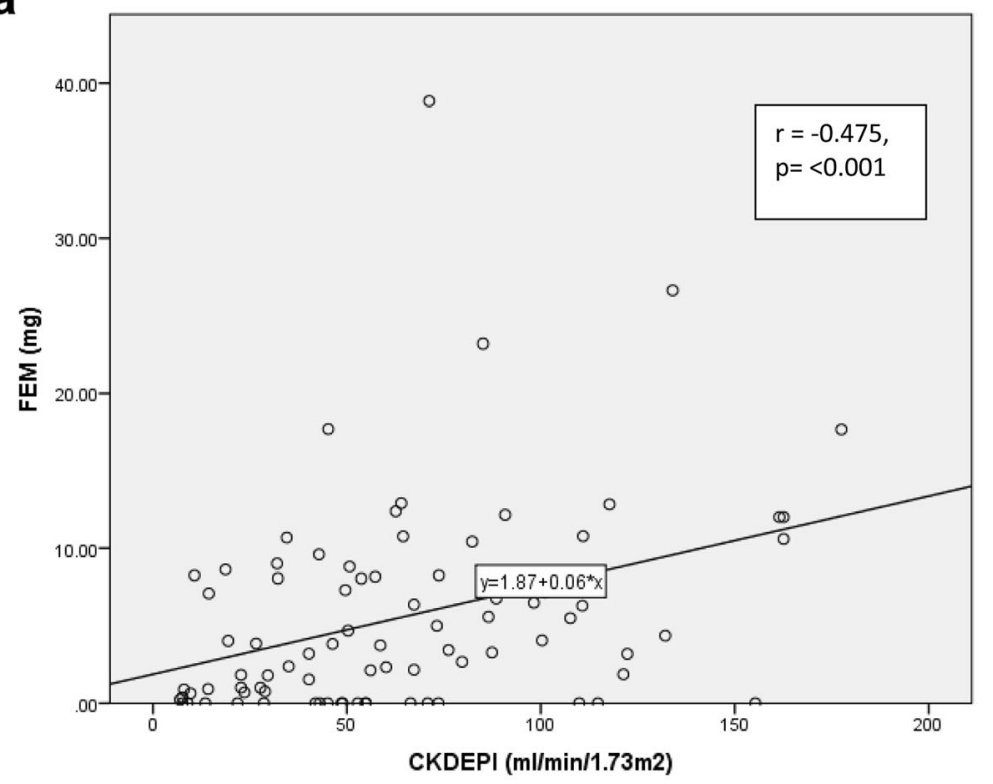

b

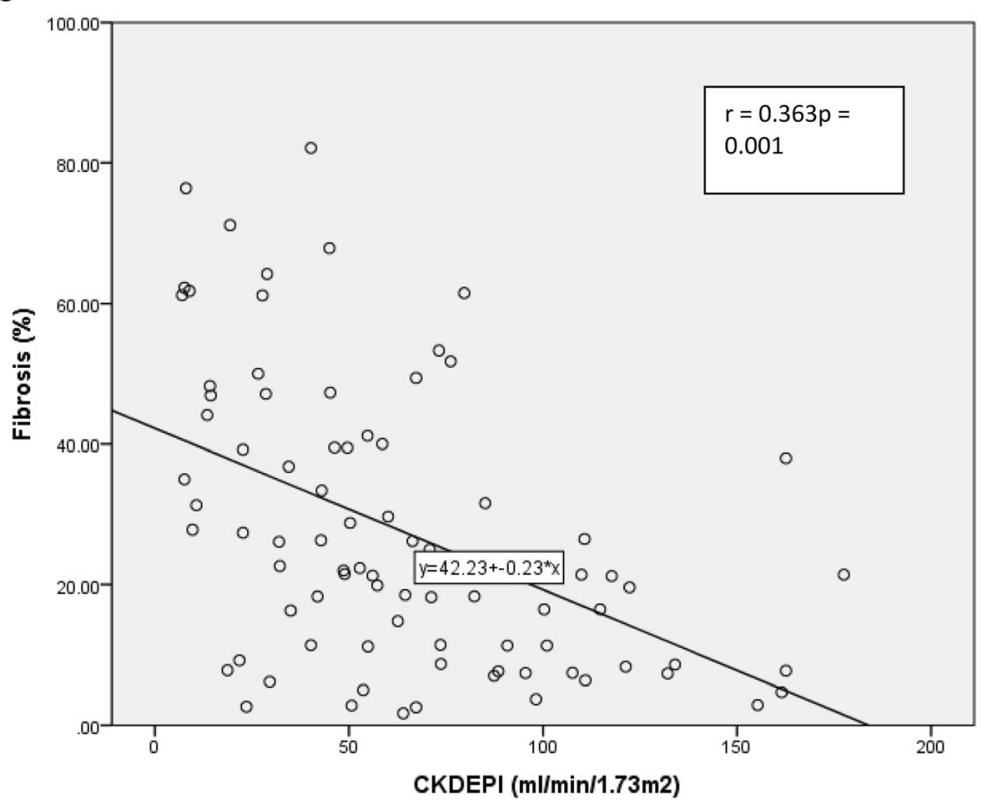

Fig. 4 a and b FEM2, fibrosis score and baseline eGFR

of the FST over kidney function decline over time. Second, the strength of the association among the different variables analyzed (interstitial fibrosis, FEM, CKDEPI and total urine output) was significant only in the subgroup of native kidneys compared to the group of renal transplantation, probably in relation to a greater renal mass and the larger sample size of the group of native kidneys Finally, although statistically significant, the correlations were not strong.

\section{Conclusions}

In conclusion, our findings support that interstitial fibrosis correlates with FST with both total urine output and the furosemide excreted mass. This could be established as non-invasive tool to evaluate interstitial fibrosis and may offer more prognostic information over eGFR and proteinuria alone. Further longitudinal studies are needed to establish if FST is associated with kidney function decline over time. 


\section{Abbreviations}

CKD: Chronic kidney disease; FEM2: Furosemide Excreted mass at $2 \mathrm{~h}$; FST: Furosemide stress test; GFR: Glomerular filtration rate; IF: Interstitial fibrosis; MFP: Morphometric fibrosis percentage; UO: Urine output

\section{Acknowledgements}

This work was presented in abstract form at the American Society of Nephrology Meeting 2018

\section{Authors' contributions}

$J R, E M, L C, R M, P V, C G, P G, M M$ were involved in the design, interpretation of results and writing of the manuscript. SV was involved in the study design and laboratory supervision, VS was the pathologist interpreting the biopsies, FR was involved with the statistical analysis, interpretation of results and writing of the manuscript. Authors' approval: All authors have read and approved the manuscript in its current state.

\section{Funding}

The research was funded by the nephrology division from the Instituto Nacional de Cardiología. The funding body had no role in the design of the study and collection, analyses, and interpretation of data and in writing the manuscript.

\section{Availability of data and materials}

The datasets used and/or analysed during the current study are available from the corresponding author on reasonable request.

\section{Ethics approval and consent to participate}

The research was approved by the institutional research ethics committee from the Instituto Nacional de Cardiologia and registered with the number 15-920. Written informed consent was obtained from all participants.

\section{Consent for publication}

NA

\section{Competing interests}

Pranav S Garimella is a member of the editorial board for BMC Nephrology.

\section{Author details}

${ }^{1}$ Nephrology Department, National Institute of Lung Disease Ismael Cosio Villegas, Mexico City, Mexico. ${ }^{2}$ Nephrology Department, National Institute Cardiology Ignacio Chávez, Juan Badiano No. 1, 14080-Tlalpan, Mexico City, Mexico. ${ }^{3}$ Division of Nephrology, University of California, San Diego, CA, USA.

\section{Received: 18 July 2019 Accepted: 11 February 2020}

\section{- 10.0}

\section{References}

1. Jha V, Garcia-Garcia G, Iseki K, et al. Chronic kidney disease: global dimension and perspectives. Lancet. 2013;382:260-72.

2. De Nicola L, Zocalli C. Chronic kidney disease prevalence in the general population: heterogeneity and concerns. Nephrol Dial Transplant. 2016;31: 331-5.

3. Liu Y. Cellular and molecular mechanisms of renal fibrosis. Nat Rev Nephrol. 2011;7:684-96.

4. Kaissling B, Hegyi I, Loffing J, et al. Morphology of interstitial cells in the healthy kidney. Anat Embryol. 1996;193:303-18.

5. Alcorn D, Maric C, McCausland J. Development of the renal interstitium. Pediatr Nephrol. 1999:13:347-54.

6. Kaissling B, Le Hir M. The renal cortical interstitium: morphological and functional aspects. Histochem Cell Biol. 2008;130:247-62.

7. Hewitson TD. Fibrosis in the kidney: is a problem shared a problem halved? Fibrogenesis Tissue Repair. 2012;5:S14.

8. Iwano M, Neilson EG. Mechanisms of tubulointerstitial fibrosis. Curr Opin Nephrol Hypertens. 2004;13:279-84

9. Tampe D, Zeisberg M. Potential approaches to reverse or repair renal fibrosis. Nat Rev Nephrol. 2014;10:226-37.

10. Portilla D. Apoptosis, fibrosis and senescence. Nephron Clin Pract. 2014;127: 65-9.

11. Nath K. Tubulointerstitial changes as a major determinant in the progression of renal damage. Am J Kidney Dis. 1992;20:1-17.
12. Mannon RB, Matas AJ, Grande J, et al. Inflammation in areas of tubular atrophy in kidney allograft biopsies: a potent predictor of allograft failure. Am J Transplant. 2010;10:2066-73.

13. Haas M. Chronic allograft nephropathy or interstitial fibrosis and tubular atrophy: what is in a name? Curr Opin Nephrol Hypertens. 2014;23:245-50.

14. Venner JM, Famulski KS, Reeve J, et al. Relationships among injury, fibrosis, and time in human kidney transplants. JCI Insight. 2016;1:e85323.

15. Smith HW. The kidney: structure and function in health and disease. New York: Oxford University Press, Inc; 1951. p. 191-2.

16. Myers GL, Miller WG, Coresh J, et al. Recommendations for improving serum creatinine measurement: a report from the laboratory working Group of the National Kidney Disease Education Program. Clin Chem. 2006;52:5-18.

17. Ferguson M, Waikar SS. Established and emerging markers of kidney function. Clin Chem. 2012;58:680-9

18. Gowda S, Desai PB, Kulkarni SS, et al. Markers of renal function tests. N Am J Med Sci. 2010;2:170-3.

19. Bauer JH, Brooks CS, Burch RN. Clinical appraisal of creatinine clearance as a measurement of glomerular filtration rate. Am J Kidney Dis. 1982;2:337-46.

20. Nilsson-Ehle P, Grubb A. New markers for the determination of GFR: lohexol clearance and cystatin C serum concentration. Kidney Int Suppl. 1994;46:S17-9.

21. Levey AS, Bosch JP, Lewis JB, et al. A more accurate method to estimate glomerular filtration rate from serum creatinine: a new prediction equation. Ann Intern Med. 1999;130:461-70.

22. Grubb AO. Cystatin C - properties and use as diagnostic marker. Adv Clin Chem. 2000:35:63-99.

23. Knight EL, Verhave JC, Spiegelman D, et al. Factors influencing serum cystatin $C$ levels other than renal function and the impact on renal function measurement. Kidney Int. 2004;65:1416-21.

24. Coresh J, Astor BC, McQuillan G, et al. Calibration and random variation of the serum creatinine assay as critical elements of using equations to estimate glomerular filtration rate. Am J Kidney Dis. 2002;39:920-9.

25. Cockcroft DW, Gault MH. Prediction of creatinine clearance from serum creatinine. Nephron. 1976;16:31-4.

26. Luke RG. Urea and the BUN. N Engl J Med. 1981;305:1213-5.

27. Herrington D, Drusano GL, Smalls U, et al. False elevation in serum creatinine levels. JAMA. 1984:252:2962.

28. Ibrahim $\mathrm{H}$, Mondress $\mathrm{M}$, Tello A, et al. An alternative formula to the Cockcroft-Gault and the modification of diet in renal diseases formulas in predicting GFR in individuals with type 1 diabetes. J Am Soc Nephrol. 2005; 16:1051-60.

29. Froissart $M$, Rossert J, Jacquot $C$, et al. Predictive performance of the modification of diet in renal disease and Cockcroft-Gault equations for estimating renal function. J Am Soc Nephrol. 2005;16:763-73.

30. Zerbe RL, Robertson GL. A comparison of plasma vasopressin measurements with a standard indirect test in the differential diagnosis of polyuria. N Engl J Med. 1981;305:1539-46.

31. Halperin ML, Richardson RM, Bear RA, et al. Urine ammonium: the key to the diagnosis of distal renal tubular acidosis. Nephron. 1988;50:1-4.

32. Batlle DC. Segmental characterization of defects in collecting tubule acidification. Kidney Int. 1986;30:546-54

33. Sabatini S, Kurtzman NA. Pathophysiology of the renal tubular acidoses. Semin Nephrol. 1991;11:202-11.

34. Carvounis CP, Nisar S, Guro-Razuman S. Significance of the fractional excretion of urea in the differential diagnosis of acute renal failure. Kidney Int. 2002;62:2223-9.

35. Rabb H. Evaluation of urinary markers in acute renal failure. Curr Opin Nephrol Hypertens. 1988;7:681-6.

36. Miller TR, Anderson RJ, Linas SL, et al. Urinary diagnostic indices in acute renal failure: Aprospective study. Ann Intern Med. 1978;88:47-57.

37. Chawla LS, Davison DL, Brasha-Mitchell E, et al. Development and standardization of a furosemide stress test to predict the severity of acute kidney injury. Crit Care. 2013;17:R207.

38. Levey AS, Stevens LA, Schmid CH, et al. A new equation to estimate glomerular filtration rate. Ann Intern Med. 2009;150:604-12.

39. Farris $A B$, Adams CD, Brousaides $N$, et al. Morphometric and visual evaluation of fibrosis in renal biopsies. J Am Soc Nephrol. 2011;22:176-86.

40. Youm I, Youan BB. Validated reverse-phase high-performance liquid chromatography for quantification of furosemide in tablets and nanoparticles. J Anal Methods Chem. 2013;2013:207028.

41. Schardijn GH, Statius van Eps LW. Beta 2-microglobulin: its significance in the evaluation of renal function. Kidney Int. 1987;32:635-41. 
42. Garimella PS, Biggs ML, Katz R, et al. Urinary uromodulin, kidney function, and cardiovascular disease in elderly adults. Kidney Int. 2015;88:1126-34.

43. Herrera J, Rodriguez-Iturbe B. Stimulation of tubular secretion of creatinine in health and in conditions associated with reduced nephron mass. Evidence for a tubular functional reserve. Nephrol Dial Transplant. 1998;13: 623-9.

44. Barai S, Gambhir S, Prasad N, et al. Functional renal reservecapacity in different stages of chronic kidney disease. Nephrology. 2010;15:350-3.

45. Udomkarnjananun $\mathrm{S}$, Townamchai $\mathrm{N}$, lampenkhae $\mathrm{K}$, et al. Furosemide stress test as a predicting biomarker for delayed graft function in kidney transplantation. Nephron. 2019;141:236-48.

46. Lumlertgul N, Peerapornratana S. Trakarnvanich Tet al. Early versus standard initiation of renal replacement therapy in furosemide stress test nonresponsive acute kidney injury patients (the FST trial). Crit Care. 2018;22:101.

47. Rewa OG, Bagshaw SM, Wang X, et al. The furosemide stress test for prediction of worsening acute kidney injury in critically ill patients: a multicenter, prospective, observational study. J Crit Care. 2019:52:109-14.

48. Van der Voort PH, Boerma EC, Pickkers P. The furosemide stress test to predict renal function after continuous renal replacement therapy. Crit Care. 2014;18:429.

\section{Publisher's Note}

Springer Nature remains neutral with regard to jurisdictional claims in published maps and institutional affiliations.

- fast, convenient online submission

- thorough peer review by experienced researchers in your field

- rapid publication on acceptance

- support for research data, including large and complex data types

- gold Open Access which fosters wider collaboration and increased citations

- maximum visibility for your research: over $100 \mathrm{M}$ website views per year

At $\mathrm{BMC}$, research is always in progress.

Learn more biomedcentral.com/submissions 